\title{
A Case Report on Concurrent Stroke and Myocardial Infarction
}

\author{
Khairy $\mathrm{M}^{1}$, Lu V $\mathrm{V}^{1}$, Ranasinghe $\mathrm{N}^{2}$, Ranasinghe $\mathrm{L}^{3^{*}}$ \\ ${ }^{1}$ Fourth-year Medical Student, California Northstate University College of Medicine, 9700 W. Taron Dr., Elk Grove, California, \\ USA \\ ${ }^{2}$ Emergency Physician, New York, USA \\ ${ }^{3}$ Professor of Emergency Medicine, California Northstate University College of Medicine, 970o W. Taron Dr., Elk Grove, \\ California, USA
}

Corresponding Author: Leonard Ranasinghe, MD

Address: Professor of Emergency Medicine. College of Medicine, 970o W. Taron Dr., Elk Grove, California 9757, USA.

Received date: 05 December 2020; Accepted date: 15 January 2021; Published date: 23 January 2021

Citation: Khairy M, Lu V, Ranasinghe N, Ranasinghe L. A Case Report on Concurrent Stroke and Myocardial Infarction. Asp Biomed Clin Case Rep. 2021 Jan 23;4(1):42-49.

Copyright (c) 2021 Khairy M, Lu V, Ranasinghe N, Ranasinghe L. This is an open-access article distributed under the Creative Commons Attribution License, which permits unrestricted use, distribution, and reproduction in any medium provided the original work is properly cited.

\begin{abstract}
Concurrent myocardial infarction and acute cerebral infarction is a rare and poorly studied phenomenon that presents a challenge to treat as both conditions are life threatening with narrow therapeutic windows. We present the case of a 70 year old female who presented with symptoms concerning for stroke. However, an electrocardiogram revealed she was also having an acute myocardial infarction. The decision was made to treat the stroke with intravenous tissue plasminogen activator. Unfortunately, the patient ultimately decompensated and died. There are many proposed etiologies of this phenomenon including cardiac thrombi leading to concurrent acute myocardial infarction and cerebral infarction, a primary myocardial infarction leading to a cerebral infarction, and a primary cerebral infarction leading to an acute myocardial infarction. Treatment options include simultaneous mechanical thrombectomy and percutaneous coronary intervention in a cardiac catheterization laboratory, or treating with the intravenous tissue plasminogen activator dose for a cerebral infarction and then potentially also proceeding to percutaneous coronary intervention. Ultimately, the management of this situation will depend on the patient's specific situation including the type of stroke, the extent of irreversible tissue damage, and the hospital's available resources. A randomized controlled study is difficult because of the rare occurrence of both presentations and a systematic review of the available literature may provide physicians with better insight as to how to approach a simultaneous acute myocardial infarction and acute cerebral infarction.
\end{abstract}

\section{Keywords}

Myocardial Infarction, Cerebral Infarction, Stroke, ST Elevation Myocardial Infarction

\section{Abbreviations}

Myocardial Infarction (MI), Percutaneous Coronary Intervention (PCI), Tissue Plasminogen Activator (tPA), Electrocardiogram (ECG), Computerized Tomography (CT), Intravenous (IV), Cardio-Cerebral Infarction (CCI), Left Ventricular (LV), Neurogenic Stunning Myocardium (NSM), High-Sensitivity (HS), American Heart Association/American Stroke Association (AHA/ASA) 


\section{Introduction}

Cardiovascular and cerebrovascular disease are major causes of death and disability globally. The simultaneous presentation of an acute myocardial infarction (MI) and acute cerebral infarction is a rare phenomenon with an incidence of $0.009 \%$ [1] and therefore has not been well studied. Both are lifethreatening conditions with narrow therapeutic windows. The dilemma in the foregoing clinical situations is determining which condition should receive initial therapy. If the patient is taken to the catheterization lab for evaluation and revascularization to treat the MI first, this will delay the management of the stroke and possibly place the patient outside of the window of thrombolysis. Conversely, if the patient undergoes mechanical thrombectomy for stroke, delaying the treatment of the MI, the latter event may progress to further myocardial damage, arrhythmias, heart failure, or shock. Additionally, dual antiplatelet therapy following percutaneous coronary intervention (PCI) for the treatment of MI would further increase the risk of cerebral hemorrhage after administration of tissue plasminogen activator (tPA) for the stroke. We describe a 70 year old female patient who presented with both an acute MI and acute cerebral infarction.

\section{Case Summary}

A 70 year old woman presented to the emergency department with slurred speech, generalized weakness, and confusion. No other symptoms were noted. Baseline vital signs were stable. Telestroke was consulted and the National Institutes of Health Stroke Scale (NIHSS) score was 2. Electrocardiogram (ECG) showed ST-segment elevation in leads V2-V6. Computerized tomography (CT) scan of the head revealed no evidence of hemorrhage or other cerebral pathology. Troponin was elevated above 6,ooo. The diagnosis was stroke and acute anterior MI. Cardiology was consulted. There was concern regarding which condition to treat first. Vital signs remained stable. Ultimately, intravenous (IV) tPA was initiated and speech improved. Unfortunately the patient decompensated and died despite receiving resuscitative measures.

\section{Discussion}

Pathogenesis:
There are multiple mechanisms that may explain the simultaneous presentation of cardio-cerebral infarction (CCI). Three processes have been proposed: (1) concurrent CCI, (2) MI leading to cerebral infarction, and (3) cerebral infarction leading to MI.

1. Cerebral and myocardial infarction may occur simultaneously in cases in which intracardiac thrombi may form with subsequent emboli dislodged to both coronary and cerebral arteries simultaneously, as confirmed by pathologic studies of retrieved thrombi in one report [2]. The Framingham Study showed that atrial fibrillation is associated with stroke by causing stasis of the blood which leads to thrombus formation which can embolize to the brain [3]. Coronary artery embolism is considered an important nonatherosclerotic cause of MI, with a reported prevalence of $2.9 \%$ in acute MIs with atrial fibrillation considered as the most common cause [4]. Intracardiac thrombogenesis may occur from left ventricular (LV) failure and subsequent left atrial dilation leading to atrial fibrillation, or from LV dysfunction producing LV segmental akinesia and dyskinesia [2,5-9]. Right ventricular thrombus or deep vein thrombosis may also give rise to paradoxical emboli through a right-to-left intracardiac shunt such as a patent foramen ovale $[10,11]$. Other causes of coronary embolism include infective endocarditis, valvular heart disease, iatrogenic causes such as cardiac catheterization, and cardiomyopathy [4,12-15]. Another possible mechanism of $\mathrm{CCI}$ is thrombogenesis secondary to coronary vasospasm. Passage of vasoactive chemicals, including serotonin in patients with carcinoid heart disease may be transmitted through a patent foramen ovale inducing coronary vasospasm resulting in a prothrombotic state and cerebrovascular injury $[10,16,17]$. Another differential diagnosis to consider as a cause of $\mathrm{CCI}$ is type A aortic dissection, which may lead to proximal extension to the coronary ostia and distal extension to the carotid or vertebral and basilar arteries [18-20]. Extension of the dissection to the coronary ostia can cause MI, and extension to the carotid or vertebral and basilar 
arteries may lead to acute cerebral infarction. The International Registry of Acute Aortic Dissection showed that the incidence of either MI or cerebrovascular accident found concurrently with Type A dissection was $4.8 \%$ and $6.1 \%$, respectively [21].

2. Acute cardiac events may result in subsequent cerebrovascular events. A right ventricular infarct complicated by severe hypotension may lead to acute cerebral infarction by reduction in cerebral perfusion [18,22-26]. MI complicated by cardiogenic shock is managed with revascularization and percutaneous mechanical circulatory support. Cardiogenic shock due to MI and clinical management are both associated with an increased risk of stroke and higher in-hospital mortality [27]. The presence of significant carotid artery disease with impaired cerebral autoregulation distal to the occlusion may be unable to adequately compensate an acute drop in blood pressure, such as in cardiogenic shock. The presence of high-grade carotid stenosis in cardiac surgery with cardiopulmonary bypass has been shown to increase risk of stroke in the perioperative period and likely associated with exhausted autoregulatory reserve [28].

3. Central autonomic dysregulation of cardiac activity from acute cerebral infarction may also lead to concurrent MI. Neurogenic myocardial injury, such as neurogenic stunning myocardium (NSM), describes a neurological event, such as cerebral infarction, complicated by autonomic neural dysregulation with cardiac manifestations [29]. Intracardiac neuronal release of catecholamines may alter cardiac function and result in myocardial cell damage [30]. Histopathological studies have shown a difference in patients with thrombotic MI compared to MI secondary to NSM. Coagulation necrosis is the pathologic hallmark of thrombotic MI [31]. MI secondary catecholamine-induced cardiac injury, in contrast, occurs as transient myofibrillar degeneration or myocytolysis surrounding epicardial nerves in the subendocardium [32,33].

A stroke in the left insular cortex, supplied by perforating branches of the middle cerebral artery, increases the risk of adverse cardiac outcomes, including MI, compared to acute cerebral infarction in other cortical regions [34,35]. The insular cortex has been implicated in NSM or in the autonomic modulation of cardiac activity [32,34,36,37]. Patients with lesions in the insular cortex have a higher rise in norepinephrine and are associated with increased frequency of arrhythmias [38].

\section{Management:}

Evaluation Considerations:

Since MI may occur concurrently or, more frequently, as a complication of acute cerebral infarction, current guidelines by the American Heart Association (AHA) recommend a cardiovascular examination comprising baseline ECG and cardiac troponin assessment in all patients presenting with acute cerebral infarction [39]. Cardiac examination focuses on identifying concurrent MI, valvular abnormalities, or irregular rhythms as a cause of a cardioembolic event [39]. Aortic dissection is a rare event but is crucial to detect as a cause of CCI, since thrombolytic therapy may worsen outcomes $[19,40,41]$. Predictors of aortic dissection may include upper extremity pulse discrepancy, widened mediastinum, and direct evidence by CT angiography, transesophageal echocardiogram, or carotid ultrasonography $[20,21,41,42]$.

Patients with acute cerebral infarction commonly present with an increase in serum cardiac troponins [43-47]. Sustained increases in cardiac troponin levels or ECG changes in patients presenting with acute cerebral infarction may be due to brain-heart axis dysregulation or other chronic comorbidities. A study measuring serial high-sensitivity (HS) cardiac troponin in patients with acute ischemic stroke found that $60 \%$ of the patients with elevated HS cardiac troponin I had sustained elevations and the remainder experienced a dynamic change suggesting that the elevated cardiac troponin levels in patients with acute cerebral infarction may not always be due to an acute MI [44]. Similarly, electrocardiographic changes in acute cerebral infarction include QT-segment prolongation, ST-segment depression, $\mathrm{T}$ wave abnormalities, and prominent U waves [46] These ECG changes have been found on initial presentation for acute cerebral 
infarction in one study while another reported these ECG changes to be new [45-47]. Although elevations in HS troponin and abnormalities on ECG in patients with ischemic stroke may not indicate concurrent MI or result from acute cerebral infarction, they may also indicate nonischemic cardiac injury and both of these findings are associated with a worse prognosis $[35,48-$ 50]. Cardiovascular risk assessment may be useful to tailor management according to the patient's clinical profile.

\section{Treatment Considerations:}

The American Heart Association/American Stroke Association (AHA/ASA) 2018 guidelines recommend (Class I) mechanical thrombectomy for patients with large vessel occlusions [39] in acute cerebral infarction but most hospitals do not have the capability to perform this procedure. However, if the institution has a cardiac catheterization laboratory, it is possible for interventional cardiologists to work closely with neurologists to perform the mechanical thrombectomy [51]. One study demonstrated restoration of blood flow in $80 \%$ of patients who underwent mechanical thrombectomy by interventional cardiologists for acute cerebral infarction [51]. This may be a setting of opportunity for neurologists and cardiologists to explore a team effort in a cardiac catheterization laboratory to perform a mechanical thrombectomy and PCI for CCI.

tPA is the standard agent of thrombolysis for stroke and is a therapeutic agent for MI as well [39]. IV-tPA alone has been considered for treatment of CCI with favorable outcomes in cases cited in literature [52]. One consideration is the difference in dosage of tPA for treating acute cerebral infarction and MI. For MI, AHA guidelines recommend a bolus of $15 \mathrm{mg}$, then an infusion of $0.75 \mathrm{mg} / \mathrm{kg}$ (not exceeding $50 \mathrm{mg}$ ) over a 30 minute period, then $0.5 \mathrm{mg} / \mathrm{kg}$ (not exceeding 35 $\mathrm{mg}$ ) over the following 60 minutes [53]. The total dose should not exceed $100 \mathrm{mg}$. The AHA/ASA 2018 guidelines recommend $0.9 \mathrm{mg} / \mathrm{kg}$ over 60 minutes for acute cerebral infarction, with $10 \%$ of the dose given during the first minute [39]. The total tPA dose should not exceed $90 \mathrm{mg}$. Administering a higher dose than recommended in acute cerebral infarction carries the risk of cerebral hemorrhagic transformation. The
AHA/ASA 2018 Guidelines for the Early Management of Patients with Acute Ischemic Stroke recommends (Class II) administering the dose for acute cerebral infarction and then proceeding to PCI. Treating with IV-tPA does not reduce the benefit of PCI [54,55].

\section{Conclusion}

The patient with an acute myocardial infarction presenting with acute cerebral infarction is a challenging situation in the emergency department as it is unknown if myocardial infarction or ischemic stroke should be treated first. The approach to management will depend on the type of stroke, extent of tissue affected, and the resources available at the hospital. Treatment must be individualized for each patient. For large cerebral vessel occlusions, mechanical thrombectomy and PCI in the same cardiac catheterization laboratory may be a solution. Another possible approach is administering the strokeappropriate dose of IPA and then performing PCI. IVtPA alone for simultaneous treatment may be considered as well, although the optimal dose is unknown. This dilemma in choosing which to treat first presents an opportunity for research. Future histopathologic studies may elucidate the cause of concurrent ischemia and provide insight into how early intervention may best prevent the rapid succession of the other. Because of the rarity of CCI, it is difficult to design a study to determine the best course of management. A systematic review of the case reports and case studies may provide physicians with better insight as to how to approach this challenge.

\section{Acknowledgements}

We thank Dr. Leonard Ranasinghe (California Northstate University College of Medicine) and Dr. Nalin Ranasinghe for providing us with this interesting case. We thank Dr. Forshing Lui (California Northstate University College of Medicine) and Dr. Ezra Amsterdam (University of California Davis School of Medicine) for comments on the manuscript. Special thanks to Ms. Brittany Alwis for editing this manuscript.

\section{Conflict of Interests}

All authors have read and approved the final version of the manuscript. The authors have no conflicts of 
Citation: Khairy M, Lu V, Ranasinghe N, Ranasinghe L. A Case Report on Concurrent Stroke and Myocardial Infarction. Asp Biomed Clin Case Rep. 2021 Jan 23;4(1):42-49.

\section{Review Article}

interest to declare.

\section{References}

[1] Yeo LLL, Andersson T, Yee KW, Tan BYQ, Paliwal P, Gopinathan A, Nadarajah M, Ting E, Teoh HL, Cherian R, Lundström E, Tay ELW, Sharma VK. Synchronous cardiocerebral infarction in the era of endovascular therapy: which to treat first? J Thromb Thrombolysis. 2017 Jul;44(1):104-11. [PMID: 28220330]

[2] Tokuda K, Shindo S, Yamada K, Shirakawa M, Uchida K, Horimatsu T, Ishihara M, Yoshimura S. Acute Embolic Cerebral Infarction and Coronary Artery Embolism in a Patient with Atrial Fibrillation Caused by Similar Thrombi. J Stroke Cerebrovasc Dis. 2016 Jul;25(7):1797-99. [PMID: 27105568]

[3] Wolf PA, Dawber TR, Thomas HE Jr, Kannel WB. Epidemiologic assessment of chronic atrial fibrillation and risk of stroke: the Framingham study. Neurology. 1978 Oct;28(10):973-77. [PMID: 570666]

[4] Shibata T, Kawakami S, Noguchi T, Tanaka T, Asaumi Y, Kanaya T, Nagai T, Nakao K, Fujino M, Nagatsuka K, Ishibashi-Ueda $\mathrm{H}$, Nishimura $\mathrm{K}$, Miyamoto Y, Kusano K, Anzai T, Goto Y, Ogawa H, Yasuda S. Prevalence, Clinical Features, and Prognosis of Acute Myocardial Infarction Attributable to Coronary Artery Embolism. Circulation. 2015 Jul 28;132(4):241-50. [PMID: 26216084]

[5] Wolf PA, Abbott RD, Kannel WB. Atrial fibrillation as an independent risk factor for stroke: the Framingham Study. Stroke. 1991 Aug;22(8):983-88. [PMID: 1866765]

[6] Lamas GA, Vaughan DE, Pfeffer MA. Left ventricular thrombus formation after first anterior wall acute myocardial infarction. Am J Cardiol. 1988 Jul 1;62(1):31-35. [PMID: 3381753]

[7] Loh E, Sutton MS, Wun CC, Rouleau JL, Flaker GC, Gottlieb SS, Lamas GA, Moyé LA, Goldhaber SZ, Pfeffer MA. Ventricular dysfunction and the risk of stroke after myocardial infarction. N Engl J Med. 1997 Jan 23;336(4):251-57. [PMID: 8995087]

[8] Sanfilippo AJ, Abascal VM, Sheehan M, Oertel LB, Harrigan P, Hughes RA, Weyman AE. Atrial enlargement as a consequence of atrial fibrillation. A prospective echocardiographic study. Circulation. 1990 Sep;82(3):792-97. [PMID: 2144217]

[9] Watson T, Shantsila E, Lip GY. Mechanisms of thrombogenesis in atrial fibrillation: Virchow's triad revisited. Lancet. 2009 Jan 10;373(9658):155-66. [PMID: 19135613]

[10] Dao CN, Tobis JM. PFO and paradoxical embolism producing events other than stroke. Catheter Cardiovasc Interv. 2011 May 1;77(6):903-909. [PMID: 21207422]

[11] Kleber FX, Hauschild T, Schulz A, Winkelmann A, Bruch L. Epidemiology of Myocardial Infarction Caused by Presumed Paradoxical Embolism via a Patent Foramen Ovale. Circ J. 2017 Sep 25;81(10):1484-89. [PMID: 28450663]

[12] Prizel KR, Hutchins GM, Bulkley BH. Coronary artery embolism and myocardial infarction. Ann Intern Med. 1978 Feb;88(2):155-61. [PMID: 626443]

[13] Caciolli S, Rostagno C, Fradella G, Margheri M, Stefano P. Coronary embolism following valve surgery. J Cardiovasc Med (Hagerstown). 2008 Apr;9(4):40617. [PMID: 18334897]

[14] Vendittelli PS, Botros B, Rosman HS, Govindaraju V, Zaitoun A, Marroush TS. Coronary Artery Embolism: Two Case Reports and a Review of the Literature. Am J Med Sci. 2019 Apr;357(4):333-37. [PMID: 30545698]

[15] Fabri J Jr, Issa VS, Pomerantzeff PM, Grinberg M, Barretto AC, Mansur AJ. Time-related distribution, risk factors and prognostic influence of embolism in patients with left-sided infective endocarditis. Int J Cardiol. 2006 Jun 28;110(3):334-39. [PMID: 16213607] [16] Lopez MF, Sarracino DA, Vogelsang M, Sutton JN, Athanas M, Krastins B, Garces A, Prakash A, Peterman S, Demirjian Z, Inglessis-Azuaje I, Feeney K, Elia M, McMullin D, Dec GW, Palacios I, Lo EH, Buonanno F, Ning M. Heart-brain signaling in patent foramen ovale-related stroke: differential plasma proteomic expression patterns revealed with a 2-pass liquid chromatography-tandem mass spectrometry discovery workflow. J Investig Med. 2012 Dec;6o(8):1122-30. [PMID: 23147404]

[17] Ning M, Lo EH, Ning PC, Xu SY, McMullin D, Demirjian Z, Inglessis I, Dec GW, Palacios I, Buonanno FS. The brain's heart - therapeutic opportunities for patent foramen ovale (PFO) and neurovascular disease. Pharmacol Ther. 2013 Aug;139(2):111-23. [PMID: 23528225]

[18] Omar HR, Fathy A, Rashad R, Helal E. Concomitant acute right ventricular infarction and ischemic cerebrovascular stroke; possible explanations. 
Int Arch Med. 2010 Oct 26;3:25. [PMID: 20977759]

[19] Cook J, Aeschlimann S, Fuh A, Kohmoto T, Chang

SM. Aortic dissection presenting as concomitant stroke and STEMI. J Hum Hypertens. 2007 Oct;21(10):818-21. [PMID: 17625590]

[20] Kawano H, Tomichi Y, Fukae S, Koide Y, Toda G, Yano K. Aortic dissection associated with acute myocardial infarction and stroke found at autopsy. Intern Med. 2006;45(16):957-62. [PMID: 16974058] [21] Hagan PG, Nienaber CA, Isselbacher EM, Bruckman D, Karavite DJ, Russman PL, Evangelista A, Fattori R, Suzuki T, Oh JK, Moore AG, Malouf JF, Pape LA, Gaca C, Sechtem U, Lenferink S, Deutsch HJ, Diedrichs H, Marcos y Robles J, Llovet A, Gilon D, Das SK, Armstrong WF, Deeb GM, Eagle KA. The International Registry of Acute Aortic Dissection (IRAD): new insights into an old disease. JAMA. 2000 Feb 16;283(7):897-903. [PMID: 10685714]

[22] Amin-Hanjani S, Pandey DK, Rose-Finnell L, Du X, Richardson D, Thulborn KR, Elkind MS, Zipfel GJ, Liebeskind DS, Silver FL, Kasner SE, Aletich VA, Caplan LR, Derdeyn CP, Gorelick PB, Charbel FT; Vertebrobasilar Flow Evaluation and Risk of Transient Ischemic Attack and Stroke Study Group. Effect of Hemodynamics on Stroke Risk in Symptomatic Atherosclerotic Vertebrobasilar Occlusive Disease. JAMA Neurol. 2016 Feb;73(2):178-85. [PMID: 26720181]

[23] Derdeyn CP, Grubb RL Jr, Powers WJ. Cerebral hemodynamic impairment: methods of measurement and association with stroke risk. Neurology. $1999 \mathrm{Jul}$ 22;53(2):251-59. [PMID: 10430410]

[24] Kario K, Shimada K, Pickering TG. Abnormal nocturnal blood pressure falls in elderly hypertension: clinical significance and determinants. J Cardiovasc Pharmacol. 2003 Jan;41 Suppl 1:S61-66. [PMID: 12688399]

[25] Somes GW, Pahor M, Shorr RI, Cushman WC, Applegate WB. The role of diastolic blood pressure when treating isolated systolic hypertension. Arch Intern Med. 1999 Sep 27;159(17):2004-2009. [PMID: 10510985]

[26] Reshef S, Fried L, Beauchamp N, Scharfstein D, Reshef D, Goodman S. Diastolic blood pressure levels and ischemic stroke incidence in older adults with white matter lesions. J Gerontol A Biol Sci Med Sci. 2011 Jan;66(1):74-81. [PMID: 21030465]
[27] Pahuja M, Chehab O, Ranka S, Mishra T, Ando T, Yassin AS, Thayer KL, Shah P, Kimmelstiel CD, Salehi P, Kapur NK. Incidence and clinical outcomes of stroke in ST-elevation myocardial infarction and cardiogenic shock. Catheter Cardiovasc Interv. 2020 Apr 30. [PMID: 32352638]

[28] Schoof J, Lubahn W, Baeumer M, Kross R, Wallesch CW, Kozian A, Huth C, Goertler M. Impaired cerebral autoregulation distal to carotid stenosis/occlusion is associated with increased risk of stroke at cardiac surgery with cardiopulmonary bypass. J Thorac Cardiovasc Surg. 2007 Sep;134(3):690-96. [PMID: 17723819]

[29] Nguyen H, Zaroff JG. Neurogenic stunned myocardium. Curr Neurol Neurosci Rep. 2009 Nov;9(6):486-91. [PMID: 19818236]

[30] Myers MG, Norris JW, Hachinski VC, Weingert ME, Sole MJ. Cardiac sequelae of acute stroke. Stroke. 1982 Nov-Dec;13(6):838-42. [PMID: 7147301]

[31] Tseung, J. Robbins and Cotran Pathologic Basis of Disease: 7th Edition. Pathology. 2005 April;37(2):190.

[32] Oppenheimer SM, Wilson JX, Guiraudon C, Cechetto DF. Insular cortex stimulation produces lethal cardiac arrhythmias: a mechanism of sudden death? Brain Res. 1991 May 31;550(1):115-21. [PMID: 1888988]

[33] Neil-Dwyer G, Walter P, Cruickshank JM, Doshi B, O'Gorman P. Effect of propranolol and phentolamine on myocardial necrosis after subarachnoid haemorrhage. Br Med J. 1978 Oct 7;2(6143):990-92. [PMID: 361155]

[34] Laowattana S, Zeger SL, Lima JA, Goodman SN, Wittstein IS, Oppenheimer SM. Left insular stroke is associated with adverse cardiac outcome. Neurology. 2006 Feb 28;66(4):477-83. [PMID: 16505298]

[35] Scheitz JF, Endres M, Mochmann HC, Audebert $\mathrm{HJ}$, Nolte $\mathrm{CH}$. Frequency, determinants and outcome of elevated troponin in acute ischemic stroke patients. Int J Cardiol. 2012 May 31;157(2):239-42. [PMID: 22326514]

[36] Oppenheimer SM, Gelb A, Girvin JP, Hachinski VC. Cardiovascular effects of human insular cortex stimulation. Neurology. 1992 Sep;42(9):1727-32. [PMID: 1513461]

[37] Smith KE, Hachinski VC, Gibson CJ, Ciriello J. Changes in plasma catecholamine levels after insula damage in experimental stroke. Brain Res. 1986 Jun 
4;375(1):182-85. [PMID: 3719356]

[38] Colivicchi F, Bassi A, Santini M, Caltagirone C. Cardiac autonomic derangement and arrhythmias in right-sided stroke with insular involvement. Stroke. 2004 Sep;35(9):2094-98. [PMID: 15272134]

[39] Powers WJ, Rabinstein AA, Ackerson T, Adeoye OM, Bambakidis NC, Becker K, Biller J, Brown M, Demaerschalk BM, Hoh B, Jauch EC, Kidwell CS, Leslie-Mazwi TM, Ovbiagele B, Scott PA, Sheth KN, Southerland AM, Summers DV, Tirschwell DL. Guidelines for the Early Management of Patients With Acute Ischemic Stroke: 2019 Update to the 2018 Guidelines for the Early Management of Acute Ischemic Stroke: A Guideline for Healthcare Professionals From the American Heart Association/American Stroke Association. Stroke. 2019 Dec;50(12):e344-18. Erratum in: Stroke. 2019 Dec;5o(12):e440-e441. [PMID: 31662037]

[40] Blankenship JC, Almquist AK. Cardiovascular complications of thrombolytic therapy in patients with a mistaken diagnosis of acute myocardial infarction. J Am Coll Cardiol. 1989 Nov 15;14(6):1579-82. [PMID: 2809020]

[41] Iguchi Y, Kimura K, Sakai K, Matsumoto N, Aoki J, Yamashita S, Shibazaki K. Hyper-acute stroke patients associated with aortic dissection. Intern Med. 2010;49(6):543-47. [PMID: 20228588]

[42] Uchino K, Estrera A, Calleja S, Alexandrov AV, Garami Z. Aortic dissection presenting as an acute ischemic stroke for thrombolysis. J Neuroimaging. 2005 Jul;15(3):281-83. [PMID: 15951413]

[43] Eggers KM, Lindahl B. Application of Cardiac Troponin in Cardiovascular Diseases Other Than Acute Coronary Syndrome. Clin Chem. 2017 Jan;63(1):22335. [PMID: 28062620]

[44] Anders B, Alonso A, Artemis D, Schäfer A, Ebert A, Kablau M, Fluechter S, Findeisen P, Hennerici MG, Fatar M. What does elevated high-sensitive troponin I in stroke patients mean: concomitant acute myocardial infarction or a marker for high-risk patients? Cerebrovasc Dis. 2013;36(3):211-17. [PMID: 24135532] [45] Fure B, Bruun Wyller T, Thommessen B. Electrocardiographic and troponin $\mathrm{T}$ changes in acute ischaemic stroke. J Intern Med. 2006 Jun;259(6):59297. [PMID: 16704560]

[46] Goldstein DS. The electrocardiogram in stroke: relationship to pathophysiological type and comparison with prior tracings. Stroke. 1979 MayJun;10(3):253-59. [PMID: 462510]

[47] Dimant J, Grob D. Electrocardiographic changes and myocardial damage in patients with acute cerebrovascular accidents. Stroke. 1977 JulAug;8(4):448-55. [PMID: 898240]

[48] Bustamante A, Díaz-Fernández B, Pagola J, Blanco-Grau A, Rubiera M, Penalba A, GarcíaBerrocoso T, Montaner J. Admission troponin-I predicts subsequent cardiac complications and mortality in acute stroke patients. Eur Stroke J. 2016 Sep;1(3):205-12. [PMID: 31008281]

[49] Kerr G, Ray G, Wu O, Stott DJ, Langhorne P. Elevated troponin after stroke: a systematic review. Cerebrovasc Dis. 2009;28(3):220-26. [PMID: 19571535]

[50] Asadi P, Zia Ziabari SM, Naghshe Jahan D, Jafarian Yazdi A. Electrocardiogram Changes as an Independent Predictive Factor of Mortality in Patients with Acute Ischemic Stroke; a Cohort Study. Arch Acad Emerg Med. 2019 Apr 27;7(1):e27. [PMID: 31432037]

[51] Guidera SA, Aggarwal S, Walton JD, Boland D, Jackel R, Gould JD, Kearins B, McGarvey J Jr, Qi Y, Furlong B. Mechanical Thrombectomy for Acute Ischemic Stroke in the Cardiac Catheterization Laboratory. JACC Cardiovasc Interv. 2020 Apr 13;13(7):884-91. [PMID: 32273100]

[52] Maciel R, Palma R, Sousa P, Ferreira F, Nzwalo H. Acute stroke with concomitant acute myocardial infarction: will you thrombolyse? J Stroke. 2015 Jan;17(1):84-86. [PMID: 25692111]

[53] Antman EM, Anbe DT, Armstrong PW, Bates ER, Green LA, Hand M, Hochman JS, Krumholz HM, Kushner FG, Lamas GA, Mullany CJ, Ornato JP, Pearle DL, Sloan MA, Smith SC Jr; American College of Cardiology; American Heart Association; Canadian Cardiovascular Society. ACC/AHA guidelines for the management of patients with ST-elevation myocardial infarction--executive summary. A report of the American College of Cardiology/American Heart Association Task Force on Practice Guidelines (Writing Committee to revise the 1999 guidelines for the management of patients with acute myocardial infarction). J Am Coll Cardiol. 2004 Aug 4;44(3):67119. Erratum in: J Am Coll Cardiol. 2005 Apr 19;45(8):1376. [PMID: 15358045]

[54] Afilalo J, Roy AM, Eisenberg MJ. Systematic 
Citation: Khairy M, Lu V, Ranasinghe N, Ranasinghe L. A Case Report on Concurrent Stroke and Myocardial Infarction. Asp Biomed Clin Case Rep. 2021 Jan 23;4(1):42-49.

\section{Review Article}

review of fibrinolytic-facilitated percutaneous coronary intervention: potential benefits and future challenges. Can J Cardiol. 2009 Mar;25(3):141-48. [PMID: 19279981]

[55] Bonnefoy E, Steg PG, Boutitie F, Dubien PY, Lapostolle F, Roncalli J, Dissait F, Vanzetto G, Leizorowicz A, Kirkorian G; CAPTIM Investigators, Mercier C, McFadden EP, Touboul P. Comparison of primary angioplasty and pre-hospital fibrinolysis in acute myocardial infarction (CAPTIM) trial: a 5-year follow-up. Eur Heart J. 2009 Jul;30(13):1598-6o6.

[PMID: 19429632] 